УДК 551.793

\title{
КОРРЕЛЯЦИОННАЯ МОДЕЛЬ ОСНОВНЫХ ГРАНИЦ В РАЗРЕЗЕ ЛИТОСФЕРЫ ПРИСВОДОВОЙ ЧАСТИ ВОРОНЕЖСКОЙ АНТЕКЛИЗЫ
}

\author{
А. И. Трегуб, Л. И. Надежка, И. Т. Ежова \\ Воронежский государственный университет
}

Поступила в редакцию 8 ноября 2017 г.

\begin{abstract}
Аннотация: статистический анализ соотношений морфометрических данных с основными разделами литосферы проведен по сейсмическому профилю Губкин - Жердевка. По результатам корреляционного анализа оценены статистические зависимости между морфометрией земной поверхности и сейсмическими границами литосферы: гранищей Конрада, границей Мохоровичича и границей переходного слоя. Для мегаблока КМА линейная связь морфометрии земной поверхности определена только с гранищей Конрада. Для Хоперского мегаблока - только с границей Мохоровичича. Для Лосевской шовной зоны зависимость отмечается со всеми основными границами. Эти особенности, возможно, могут быть связаны с различной историей формирования блоков фундамента.
\end{abstract}

Ключевые слова: корреляиионная модель, земная поверхность, литосфера, Воронежская антеклиза.

\section{THE CORRELATION MODEL OF THE MAIN BONDARIES IN THE LITHOSPHERE SECTION OF THE ARCH PART OF THE VORONEZH ANTECLINE}

\begin{abstract}
: statistical analysis of the morphometric data relations with the main sections of the lithosphere was carried out according to the seismic profile Gubkin-Zherdevka. According to the results correlation analysis evaluated the statistical relationship between the morphometry of the earth's surface and seismic boundaries: the boundary of Conrad, Mohorovichich's boundary and the boundary of the transition layer. For megablock KMA linear relationship of the earth's surface morphometry is determined only with the Conrad boundary. For Khopersky megablock of the only border Mohorovichich's. For Ljsevskaya suture zone of dependence exists with major borders. These features are likely to be associated with different formation history of the basement blocks.
\end{abstract}

Key words: correlation model, Earth surface, lithosphere, Voronezh antecline.

Структура литосферы Воронежского кристаллического массива представлена моделью, базирующейся на анализе комплекса геофизических данных. В ней, помимо осадочного слоя, выделяются три основных слоя в консолидированной части земной коры: гранитогнейсовый, «диоритовый», метабазитовый. Кроме того, может быть выделен слой в качестве переходного к мантии [1]. Границы между указанными подразделениями разреза литосферы выделены по геофизическим данным. Вместе с тем, существует еще одна граница - граница между литосферой и географической оболочкой. Она характеризуется рельефом земной поверхности. Тесная связь этой границы с особенностями геологического строения и тектоническими движениями отмечена в многочисленных публикациях, посвященных структурной геоморфологии, в том числе и для характеризуемой территории [2, 3]. В настоящей работе приведены результаты изучения возможной связи количественных параметров рельефа земной поверхности с глубинными границами в разрезе литосферы сводовой части Воронежской антеклизы. В качестве морфометрического параметра использован коэффициент изрезанности земной поверхности [4].

Статистический анализ соотношений морфометрических данных с важнейшими разделами литосферы проведен по имеющемуся сейсмическому профилю Губкин - Жердевка в целом и по наиболее крупным структурным элементам докембрийского фундамента в его пределах: мегаблоку КМА, Лосевской шовной зоне, а также Хоперскому мегаблоку [5, 6] (рис.1).

Для гистограмм распределения параметров этих поверхностей характерен полимодальный тип, отражающий неоднородность выборки (рис.2). Наиболее отчетливо выделяются три моды, каждая из которых 


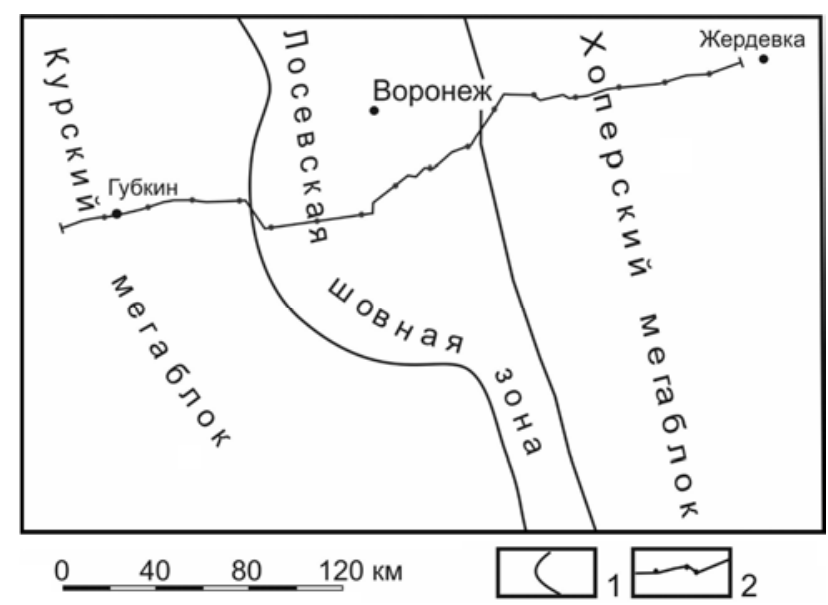

Puc. 1. Схема расположения сейсмического профиля: 1 границы мегаблоков, 2 - линия профиля. близка к соответствующим среднеарифметическим значениям коэффициента изрезанности земной поверхности; глубины залегания сейсмических границ в разрезе литосферы для трех названных выше элементов блоковой структуры фундамента (табл.1).

Так, для коэффициента изрезанности рельефа модальные значения составляют: 0,50-0,525, что с учетом стандартного отклонения соответствует среднему значению для мегаблока КМА $(0,48) ; 0,325-0,35$ (соответствует среднему значению для Лосевской шовной зоны); 0,225-0,25, что близко к среднему значению для Хоперского мегаблока $(0,28)$. Для подошвы гранитогнейсового слоя модальные значения выделяются весьма отчетливо для глубин 5 км, 11 км, 15 км. Они весьма близки к средним значениям 5,19 км (для Хоперского мегаблока); 12,20 км (для мегаблока КМА) и 13,72 км (для Лосевской шовной
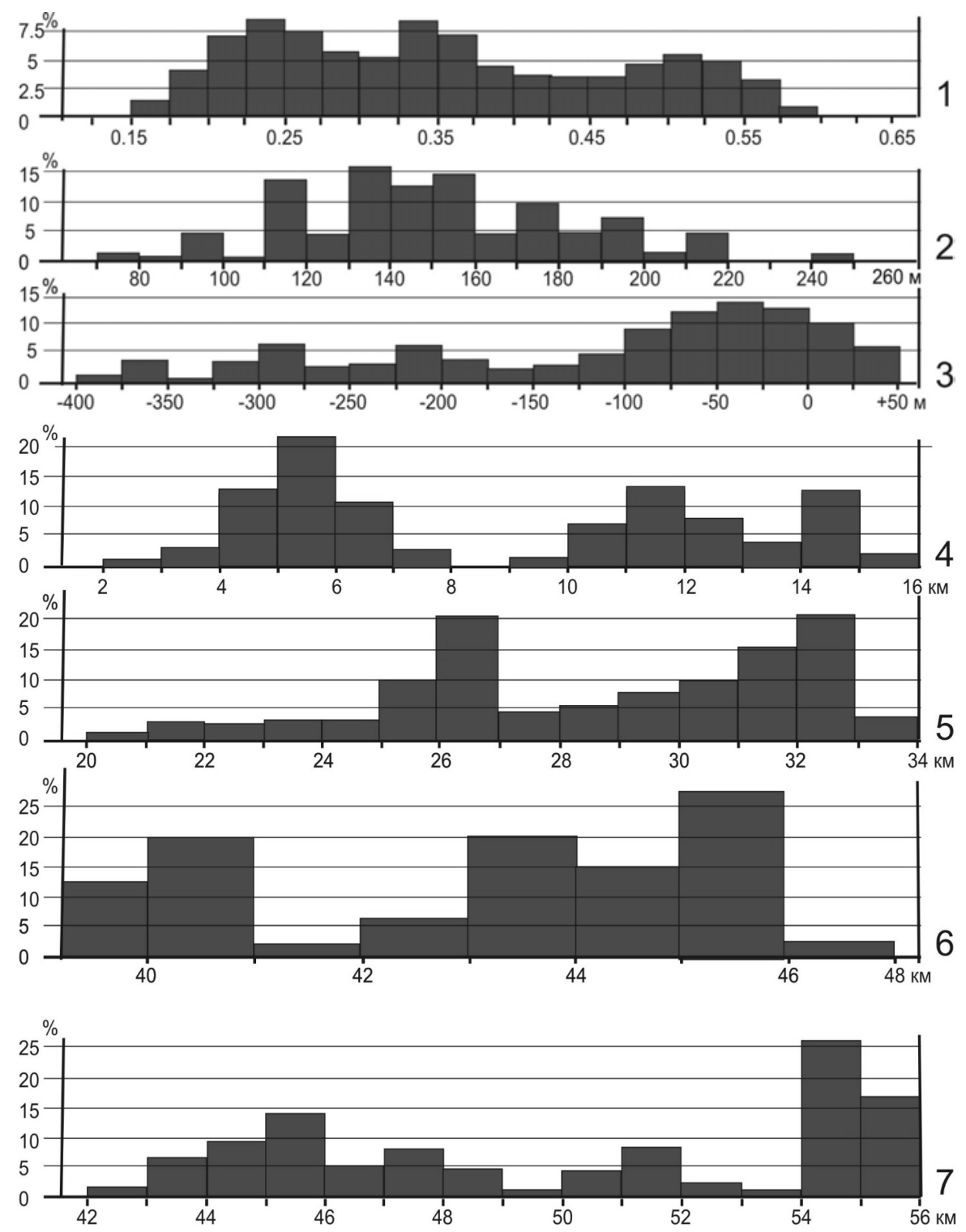

Puc. 2. Гистограммы распределения для: 1 - коэффициента изрезанности земной поверхности; 2 - гипсометрии земной поверхности; 3 - гипсометрии поверхности докембрийского фундамента; 4 - глубины подошвы гранитогнейсового слоя; 5 глубины подошвы «диоритового» слоя; 6 - глубины раздела Мохоровичича; 7 - глубины подошвы переходного слоя. 
Параметры границ в разрезе литосферы в блоках фундамента

\begin{tabular}{|c|c|c|c|c|}
\hline Блоки фундамента & Мегаблок КМА & $\begin{array}{c}\text { Лосевская } \\
\text { шовная зона }\end{array}$ & $\begin{array}{c}\text { Хоперский } \\
\text { мегаблок }\end{array}$ & $\begin{array}{c}\text { Профиль в } \\
\text { целом }\end{array}$ \\
\hline \multicolumn{5}{|c|}{ Коэффиичент изрезанности земной поверхности } \\
\hline Среднее значение & 0,48 & 0,35 & 0,28 & 0,34 \\
\hline Стандартное отклонение & 0,04 & 0,30 & 0,06 & 0,18 \\
\hline \multicolumn{5}{|c|}{ Гипсометрия земной поверхности, м } \\
\hline Среднее значение & 182,46 & 158,88 & 140,85 & 153,81 \\
\hline Стандартное отклонение & 38,36 & 40,10 & 13,66 & 35,23 \\
\hline \multicolumn{5}{|c|}{ Гипсометрия поверхности фундамента, $м$} \\
\hline Среднее значение & $-106,15$ & $+10,6$ & $-117,6$ & $-87,30$ \\
\hline Стандартное отклонение & 224,9 & 5,1 & 101,5 & 157,11 \\
\hline \multicolumn{5}{|c|}{ Глубина подошвы гранитогнейсового слоя, км } \\
\hline Среднее значение & 12,20 & 13,72 & 5,19 & 9,28 \\
\hline Стандартное отклонение & 1,58 & 1,19 & 0,86 & 4,06 \\
\hline \multicolumn{5}{|c|}{ Глубина подошвы диоритового слоя, км } \\
\hline Среднее значение & 30,52 & 25,86 & 28,56 & 28,6 \\
\hline Стандартное отклонение & 1,4 & 0,49 & 3,96 & 3,27 \\
\hline \multicolumn{5}{|c|}{ Глубина границы Мохоровичича, км } \\
\hline Среднее значение & 40,45 & 42,83 & 43,27 & 43,00 \\
\hline Стандартное отклонение & 1,62 & 2,47 & 1,77 & 2,60 \\
\hline \multicolumn{5}{|c|}{ Глубина подошвы переходного слоя, км } \\
\hline Среднее значение & 45,76 & 54,09 & 50,27 & 50,95 \\
\hline Стандартное отклонение & 1,92 & 1,59 & 3,06 & 4,30 \\
\hline
\end{tabular}

зоны). На графике для подошвы «диоритового» слоя выделяются две моды - 26-27 км и 32-33 км. Они могут быть сопоставлены со средними значениями глубины 25,86 км (Лосевская шовная зона), а также с мегаблоком КМА (30,52 км), в совокупности с Хоперским мегаблоком (28,56 км с учетом стандартного отклонения - 3,96 км). Для границы Мохоровичича установлены три преобладающие значения глубины: 40-41, 43-44, и 45-46 км, что может соответствовать средним значениям 40,45 км (мегаблок КМА), 42,83 км (Лосевская шовная зона) и 43,27 км (Хоперский мегаблок). Средние значения глубин для подошвы переходного слоя составляют: 45,76 км (мегаблок КМА), 54,09 км (Лосевская шовная зона), 50,27 км (Хоперский мегаблок). На графике функции плотности распределения им соответствуют: две сближенные моды (45 км и 48 км), а также 54-55 км и 51-52 км.

Исключение составляют гистограммы распределения абсолютных отметок современного рельефа, а также абсолютных отметок поверхности докембрийского фундамента. В первом случае график отражает весьма неоднородное распределение, которое, повидимому, может быть объяснено существенным влиянием на формирование рельефа экзогенной составляющей, вуалирующей его связь с тектоническими движениями. Для поверхности фундамента, несмотря на наличие слабо выраженных модальных значений, они существенно отличаются от средних значений по блоковой структуре. Однако если учесть большие стандартные отклонения, то эти величины будут сопоставимы: $-106+(-224)=-330$ м (мегаблок КМА); $+10,6=5,1=15,7$ м (Лосевская шовная зона $) ;-101+(-$
$117)=218$ м (Хоперский мегаблок). Таким образом, сравнение статистических данных позволяет предположить наличие связи морфометрии земной поверхности (коэффициента изрезанности) с основными блоками докембрийского фундамента. Важно отметить также, что наиболее крупные структурные элементы докембрийского фундамента (мегаблок КМА, Лосевская шовная зона, Хоперский мегаблок) находят свое отражение в особенностях топографии главных сейсмических границ в разрезе литосферы.

Для оценки связи средних значений коэффициента изрезанности со средним положением границ в разрезе литосферы вычислены коэффициенты корреляции для основных блоков фундамента и для профиля в целом. Значимость коэффициентов определенна в соответствии с критерием Стьюдента (табл.2).

По полученным данным составлены уравнения линейной регрессии разделов литосферы по коэффициенту изрезанности земной поверхности. При этом учтены только значимые по критерию Стьюдента коэффициенты корреляции (табл.3).

Для профиля в целом линейные связи коэффициента изрезанности устанавливаются с абсолютными отметками рельефа и всеми сейсмическими границами в разрезе литосферы. Отсутствует она с гипсометрией поверхности фундамента. При этом минимальные погрешности уравнения регрессии $(4,57 \%)$ отмечены для подошвы переходного слоя. Иные соотношения отмечаются для основных структурных элементов фундамента.

Для мегаблока КМА линейная зависимость с ошибкой 9,51\% в уравнении регрессии устанавливается только для подошвы верхней коры (гранитогней- 
Коэффициенты корреляции изрезанности земной поверхности и параметров основных грании в разрезе литосферы *

\begin{tabular}{|c|c|c|c|}
\hline Мегаблоки фундамента & $\begin{array}{c}\text { Коэффициент } \\
\text { корреляции }\end{array}$ & $\begin{array}{c}\mathrm{t} \text { (расчетное } \\
\text { значение) }\end{array}$ & $\begin{array}{c}\mathrm{t} \text { (табличное } \\
\text { значение) }\end{array}$ \\
\hline \multicolumn{4}{|c|}{ Коэффициент изрезанности и гипсометрия земной поверхности } \\
\hline Мегаблок КМА & $+0,16$ & - & - \\
\hline Лосевская шовная зона & $+0,58$ & 1,754 & 2,447 \\
\hline Хоперский мегаблок & $+0,10$ & - & - \\
\hline Профиль в целом & $+\mathbf{0 , 5 5}$ & 4,086 & 2,021 \\
\hline \multicolumn{4}{|c|}{ Коэффициент изрезанности и гипсометрия поверхности фундамента } \\
\hline Мегаблок КМА & $-0,55$ & 2,094 & 2,228 \\
\hline Лосевская шовная зона & $-0,42$ & 1,130 & 2,447 \\
\hline Хоперский мегаблок & $-0,18$ & - & - \\
\hline Профиль в целом & $-0,09$ & - & - \\
\hline \multicolumn{4}{|c|}{ Коэффиииент изрезанности и глубина подошвы гранитогнейсового слоя } \\
\hline Мегаблок КМА & $+\mathbf{+ 0 , 6 8}$ & 2,944 & 2,228 \\
\hline Лосевская шовная зона & $-0,95$ & 7,508 & 2,447 \\
\hline Хоперский мегаблок & $-0,08$ & - & - \\
\hline Профиль в целом & $+\mathbf{0 , 5 9}$ & 4,545 & 2,021 \\
\hline \multicolumn{4}{|c|}{ Коэффициент изрезанности и глубина подошвы «диоритового» слоя } \\
\hline Мегаблок КМА & $+0,33$ & - & - \\
\hline Лосевская шовная зона & $+0,41$ & 1,103 & 2,447 \\
\hline Хоперский мегаблок & $+0,30$ & - & - \\
\hline Профиль в целом & $+\mathbf{0 , 3 3}$ & 2,190 & 2,021 \\
\hline \multicolumn{4}{|c|}{ Коэффициент изрезанности и глубина границы Мохоровичича } \\
\hline Мегаблок КМА & $+0,42$ & 1,475 & 2,228 \\
\hline Лосевская шовная зона & $-0,77$ & 2,994 & 2,447 \\
\hline Хоперский мегаблок & $+\mathbf{0 , 6 0}$ & 3,270 & 2,093 \\
\hline Профиль в целом & $-0,59$ & 4,545 & 2,021 \\
\hline \multicolumn{4}{|c|}{ Коэффициент изрезанности и глубина подошвы переходного слоя } \\
\hline Мегаблок КМА & 0,40 & - & - \\
\hline Лосевская шовная зона & $-0,84$ & 3,811 & 2,447 \\
\hline Хоперский мегаблок & $-0,32$ & - & - \\
\hline Профиль в целом & $-0,52$ & 3,817 & 2,021 \\
\hline
\end{tabular}

*Жирным шрифтом выделены значимые по критерию Стьюдента (t) коэффициенты корреляции.

Таблица 3

Уравнения линейной регрессии поверхностей литосферы (y) по коэффициенту изрезанности $(x)$

\begin{tabular}{|c|c|c|c|}
\hline Разделы литосферы & Уравнение регрессии & Абсолютная погрешность & Относительная погрешность \\
\hline \multicolumn{4}{|c|}{ Для профиля в ичелом } \\
\hline Земная поверхность & $\mathrm{y}=117,24+107,65 \mathrm{x}$ & $29,42 \mathrm{M}$ & $19,13 \%$ \\
\hline $\begin{array}{l}\text { Подошва } \\
\text { гранитогнейсового слоя }\end{array}$ & $y=4,76+13,31 x$ & 3,28 км & $35,32 \%$ \\
\hline Подошва «диоритового» слоя & $y=26,56+5,99 x$ & 3,08 км & $10,79 \%$ \\
\hline Граница Мохоровичича & $y=45,89-8,52 x$ & 4,84 км & $11,27 \%$ \\
\hline Подошва переходного слоя & $y=44,12-20,10 x$ & 2,33 км & $4,57 \%$ \\
\hline \multicolumn{4}{|c|}{ Для мегаблока КМА } \\
\hline Разделы литосферы & Уравнение регрессии & Абсолютная погрешность & Относительная погрешность \\
\hline $\begin{array}{l}\text { Подошва } \\
\text { гранитогнейсового слоя }\end{array}$ & $y=26,86 x-0,69$ & 1,16 км & $9,51 \%$ \\
\hline \multicolumn{4}{|c|}{ Для Лосевской шовной зоны } \\
\hline Разделы литосферы & Уравнение регрессии & Абсолютная погрешность & Относительная погрешность \\
\hline $\begin{array}{l}\text { Подошва } \\
\text { гранитогнейсового слоя }\end{array}$ & $y=14,54-1,70 x$ & 2,68 км & $1,96 \%$ \\
\hline Граница Мохоровичича & $y=65,65-47,55 x$ & 1,58 км & $3,68 \%$ \\
\hline Подошва переходного слоя & $\mathrm{y}=70,12-33,39 \mathrm{x}$ & 0,86 км & $1,59 \%$ \\
\hline \multicolumn{4}{|c|}{ Для Хоперского мегаблока } \\
\hline Разделы литосферы & Уравнение регрессии & Абсолютная погрешность & Относительная погрешность \\
\hline Граница Мохоровичича & $y=38,31+17,7 x$ & 1,42 км & $3,27 \%$ \\
\hline
\end{tabular}


сового слоя). Для Хоперского мегаблока - только для подошвы земной коры в целом (погрешность в уравнении регрессии 3,27 \%). На этом фоне резко выделяется Лосевская шовная зона, в пределах которой линейная связь коэффициента изрезанности с небольшими погрешностями в уравнениях регрессии проявляется для всех сейсмических границ, за исключением «диоритового» слоя.

Отмеченные особенности, по-видимому, могут быть обусловлены двумя причинами - геологической историей формирования основных структурных элементов и их современной геодинамической активностью, проявленной в степени изрезанности земной поверхности. Мегаблок КМА обладает наиболее древней и «легкой» (по А. П. Таркову) литосферой [7]. Это в целом подтверждено и существенно дополнено более поздними исследованиями [8-10]. В пределах мегаблока в области сейсмического профиля распространен гранитоидный тип коры со средней плотностью

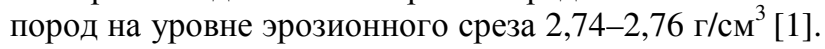
Земная поверхность здесь обладает наиболее высокими средними абсолютными отметками. Среднее значение коэффициента изрезанности также большое с незначительной величиной среднеквадратического отклонения. Коэффициент корреляции изрезанности земной поверхности и глубины подошвы слоя верхней коры $(+0,68)$ свидетельствует о заметной (по К. Пирсону) тесноте связи между этими параметрами [11].

Хоперский мегаблок характеризуется «тяжелой» литосферой [7-10]. В области сейсмического профиля он представлен метабазитовым типом коры со сред-

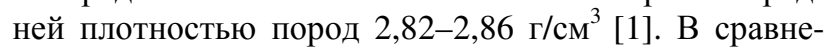
нии с мегаблоком КМА Хоперский мегаблок является более молодым, он сформировался в раннем протерозое в результате субдукционных процессов [9]. Средняя абсолютная отметка земной поверхности имеет минимальное значение с минимальным разбросом. Степень изрезанности также имеет устойчиво минимальную величину. Оценка связи по коэффициенту корреляции $(+0,60)$ между изрезанностью и глубиной подошвы коры относится к заметной.

Лосевская шовная зона - результат коллизии конца палеопротерозоя [9]. Она характеризуется резким преобладанием коры гранитоидного типа [1]. Средняя абсолютная отметка поверхности Земли занимает промежуточное значение между разделяемыми шовной зоной мегаблоками, но отличается большой величиной стандартного отклонения. Подобными соотношениями обладает и степень изрезанности. В рельефе фундамента зона выражена выступом с положительными абсолютными отметками. Лосевская шовная зона характеризуется большими значениями коэффициента корреляции, отмечающими высокую тесноту отрицательной связи между изрезанностью земной поверхности и подошвой коры $(-0,77)$, изрезанностью и подошвой переходного слоя $(-0,84)$, а для подошвы верхней коры теснота связи оценивается как весьма высокая $(-0,95)$. Таким образом, в сравнении с разделяемыми ею мегаблоками Лосевская шовная зона об- ладает большой изменчивостью всех рассматриваемых параметров, свидетельствующих о возможной повышенной ее геодинамической активности.

Выявленные закономерности, с одной стороны, можно попытаться объяснить резкой перестройкой структурного плана территории на неотектоническом этапе ее развития в условиях меридионального сжатия [3]. При этом реактивное растяжение в широтном направлении могло привести к ослаблению связей между блоками литосферы и к активизации изостатических движений, унаследовано и с разной интенсивностью продолжающихся в настоящее время. Наиболее отчетливо эти процессы проявлены в пределах неустойчивой Лосевской шовной зоны, которая характеризуется и повышенной концентрацией эпицентров землетрясений [4]. Для соседних с ней мегаблоков положительные значения коэффициентов корреляции могут свидетельствовать о том, что на современном этапе наблюдаются лишь остаточные явления. Основные изостатические движения происходили в среднем миоцене, когда наиболее отчетливо обозначилась граница между Среднерусским поднятием, охватывающим мегаблок КМА, а также Лосевскую шовную зону, и Окско-Донской депрессией, сформировавшейся над Хоперским мегаблоком [2, 3, 12].

С другой стороны, положительная связь изрезанности земной поверхности только с границей Конрада в пределах мегаблока КМА и только с границей Мохоровичича в пределах Хоперского мегаблока, повидимому, может быть обусловлена различным возрастом и условиями их формирования. Мегаблок КМА, как структура, испытавшая более длительное поднятие, проявляется на всех этапах формирования осадочного чехла $[3,13]$.

Уравнения регрессии, полученные в результате проведенных исследований, с определенной осторожностью могли бы быть использованы для предварительного определения глубин залегания сейсмических разделов: подошвы верхней коры в пределах мегаблока КМА, поверхности Мохоровичича в пределах Хоперского мегаблока. Особое место в этом отношении занимает Лосевская шовная зона, где данные по морфометрии могли бы быть использованы для определения глубин залегания разделов Конрада, Мохоровичича, а также подошвы переходного слоя. Однако при этом необходимо учитывать то обстоятельство, что проведенные расчеты выполнены по средним значениям гипсометрии поверхностей, а эта гипсометрия характеризуется достаточно большими стандартными отклонениями от средних значений. Это в значительной степени понижает достоверность регрессионных моделей.

\section{ЛИТЕРАТУРА}

1. Литосфера Воронежского кристаллического массива по геофизическим и петрофизическим данным / Н. С. Афанасьев [и др.]. Главн. ред. член-корр. РАН Н. М. Чернышов. Воронеж: «Научная книга», 2012. - 330 с.

2. Раскатов, Г. И. Геоморфология и неотектоника территории Воронежской антеклизы / Г. И. Раскатов. - Воронеж: изд-во ВГУ, 1969. - 164 с. 
3. Трегуб, А. И. Неотектоника территории Воронежского кристаллического массива // Труды НИИ геологии Воронежского госуниверситета. - Вып. 9. - Воронеж: изд-во Воронеж. ун-та, 2002. - $220 \mathrm{c}$.

4. Ежсова, И. Т. Степень изрезанности рельефа земной поверхности ВКМ и её соотношение с новейшей структурой и сейсмичностью / И. Т. Ежова, Л. И. Надежка, А. И. Трегуб // Структура, свойства, динамика и минерагения литосферы Восточно-Европейской платформы. Мат-лы XVI международной конференции. Т. 1. - Воронеж, 2010. - С. 255 - 258.

5. Структурно-тектоническое районирование Воронежского кристаллического массива (по геологическим и геофизическим данным) / Н. М. Чернышов [и др.] // Мат-лы юбилейной научной сессии геологического факультета ВГУ. Воронеж: изд-во Воронеж. ун-та, 1998. - С. 5-7.

6. Надежка, Л. И. Блоки земной коры Воронежского кристалического массива и их отражение в особенностях рельефа дневной поверхности / Л. И. Надежка, И. Т. Ежова, А. И. Дубянский // Активные разломы и их значение для оценки сейсмической опасности: современное состояние проблемы: материалы 19 научно-практической конференции с международным участием. - Воронеж, 2014. - С. 257-261.

7. Тарков, А. П. Глубинное строение Воронежского массива по геофизическим данным / А. П. Тарков. - М.: Недра, 1974. $-172 \mathrm{c}$.

Воронежский государственный университет

Трегуб Александр Иванович, доктор геолого-

минералогических наук,профессор кафедры общей геологии и геодинамики

E-mail:tregubai@yandex.ru

Тел.: 8-905-657-82-33

Надежка Людмила Ивановна, заведующая лабораторией глубинного строения, геодинамики и сейсмического мониторинга Воронежского кристаллического массива ФИЦ ЕГС РАН им. проф. А. П. Таркова

E-mail: nadezhka@geophys.vsu.ru; Тел.: 8(473) 255-78-44

Ежова Ирина Трофимовна, ведущий инженер лаборатории глубинного строения, геодинамики и сейсмического мониторинга им. проф. А. П. Таркова

E-mail: iritroe@mail.ru

Тел.: 8-951-850-61-58
8. Муравина, О. М. Плотностная модель земной коры Воронежского кристаллического массива / О. М. Муравина // Вестн. Воронеж. ун-та. Сер.: Геология. - 2016. - № 1. - С. $108-114$.

9. Глазнев, В. Н. Плотностное моделирование земной коры центральной части Восточно-Европейской платформы / В. Н. Глазнев, М. В. Минц, О. М. Муравина // Вестник КРАУНЦ, Сер. Науки о Земле. - 2016. - № 1. - С. 53-63.

10. Минц, М. В. Глубинное строение коры юго-востока Воронежского кристаллического массива по геофизическим данным: геодинамическая эволюция в палеопротерозое и современное состояние коры / М. В. Минц, В. Н. Глазнев, О. М. Муравина // Вестн. Воронеж. ун-та. Сер.: Геология. 2017. - № 4. - C. 5-23.

11. Кремер, Н. М. Теория вероятностей и математическая статистика / Н. М. Кремер. - М.: ЮНИТИ, 2002. - 543 с.

12. Минерагенические исследования территорий с двухъярусным строением (на примере Воронежского кристаллического массива) / В. М. Ненахов [и др.] // Главный ред. Н. В. Межеловский. - М.: ГЕОКАРТ, ГЕОС, 2007. - 284 с.

13. Трегуб, А. И. Литологические особенности разрезов палеозоя как отражение структурного каркаса Воронежского кристаллического массива /А. И. Трегуб // Вестник Воронеж. ун-та. Серия: Геология. - 2014. - № 3. - С.74-78.

\section{Voronezh State University}

Tregub A. I., Doctor of Geological and Mineralogical Sciences, Professor of the General Geology and Geodynamics Department

E-mail: tregubai@yandex.ru Tel.: 8-905-657-82-33

Nadezhka L. I., Head of the Tarkov Laboratory of deep Structure, Geodinamik and Seismic monitoring Voronezh Crystalline Massif FITS EGS RAS

E-mail: nadezhka@geophys.vsu.ru Tel.: 8(473) 255-78-44

Ezhova I. T., Senior Researcher of a Tarkov Laboratory of deep structure, geodinamik and seismic monitoring Voronezh Crystalline Massif FITS EGS RAS

E-mail: iritroe@mail.ru

Tel.: 8-951-850-61-58 